\title{
Evaluation of Indoor Environmental Quality in a College Teaching and Administrative Building
}

R. Todd Niemeier, MS, CIH Elena Page, MD, MPH Gregory Burr, CIH

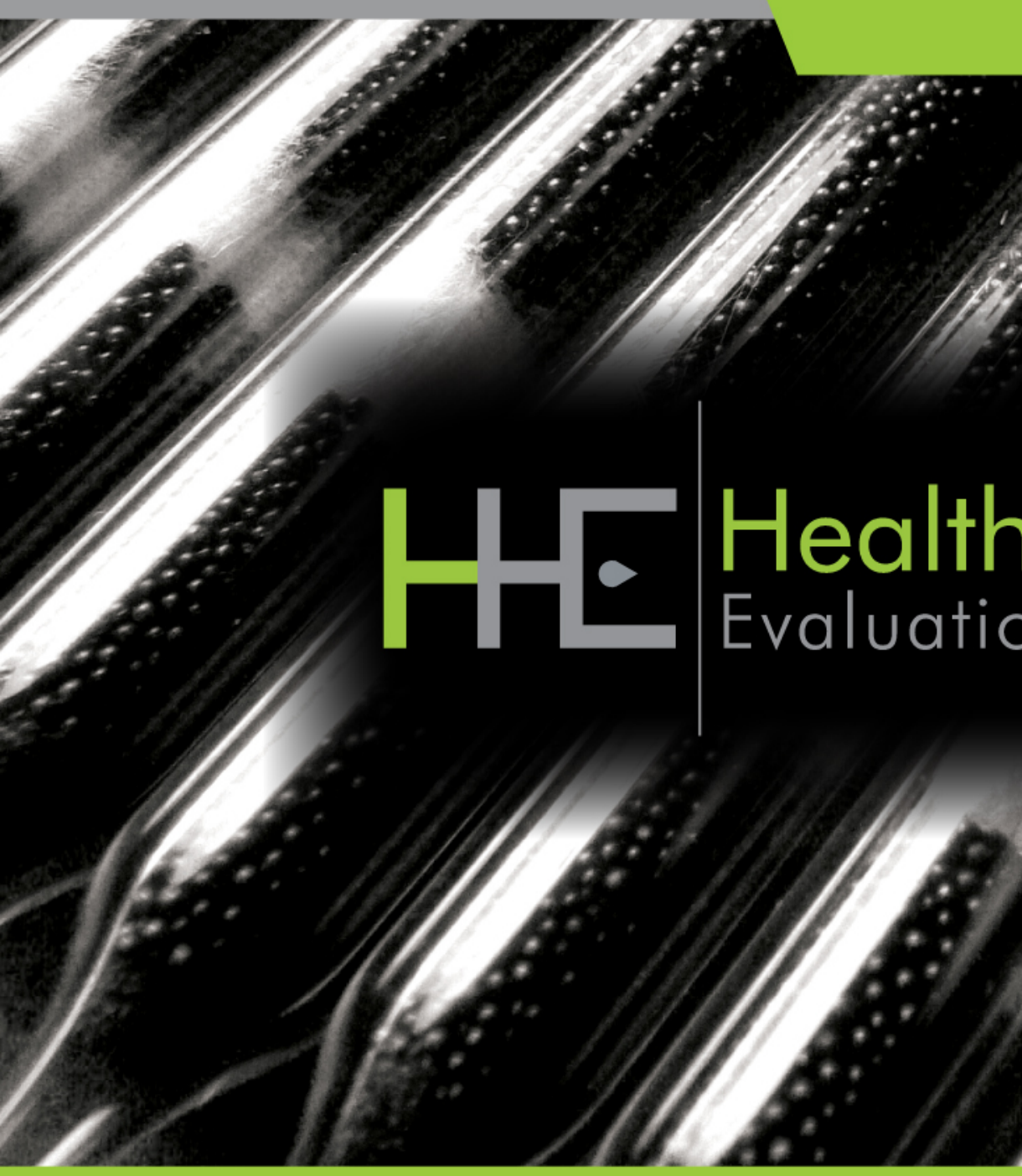

Report No. 2013-0074-3229

February 2015 


\section{Contents}

Highlights...........................................i

Introduction ............................................ 1

Methods............................................. 1

Results ................................................... 2

Discussion ............................................. 6

Conclusions ........................................ 9

Recommendations............................. 9

References...................................... 11

Acknowledgements......................... 15

The employer is required to post a copy of this report for 30 days at or near the workplace(s) of affected employees. The employer must take steps to ensure that the posted report is not altered, defaced, or covered by other material.

The cover photo is a close-up image of sorbent tubes, which are used by the HHE Program to measure airborne exposures. This photo is an artistic representation that may not be related to this Health Hazard Evaluation. Photo by NIOSH. 


\section{Highlights of this Evaluation}

The Health Hazard Evaluation Program received a request from an employer representative at a college. Employees were concerned about perceived poor indoor environmental quality in a campus building.

\section{What We Did}

- We conducted a walk-through survey of the building in May 2013.

- We looked for past or current water damage, water entering the building, and mold.

- We looked at ventilation system drawings and maintenance records and reports from consultants who looked at indoor environmental quality.

- We reviewed the college's summary of symptoms reported by employees and students.

- We interviewed current and former college faculty, managers, and staff.

\section{What We Found}

- The building was mostly unoccupied.

- We saw no evidence of current or past water damage, water entering the building, or mold.

- The ventilation systems were well maintained but mixed return air from offices, classrooms, and the dental clinic with outdoor air before returning the air back into the building.

- The ventilation system pushed air out of the dental clinic to other areas.

- Some employees were using portable ionizing air cleaners.

- A sewer pipe vented into a cabinet in the dental laboratory

- Most interviewed employees reported nonspecific symptoms common to workplaces and in the general population. We could not link these symptoms to any specific workplace exposure.

We evaluated a mostly unoccupied campus building. We found no current water damage but did find an uncapped plumbing vent. The ventilation systems mixed return air from offices, classrooms, and the dental clinic, and air in the dental clinic could be pushed into surrounding areas. One employee may have had a lung condition that could be caused by mold exposure, and this employee worked in the building when mold had been found. We do not believe that the other health problems reported by staff were workrelated. We recommended the college stop sampling to identify a cause for symptoms among building occupants and check with a ventilation engineer to change how the return air is mixed and to improve airflow.

- One employee may have had a lung condition that could be caused by mold exposure. This employee worked in the building in 2001 when mold problems were found. 


\section{What the Employer Can Do}

- Check with a ventilation engineer to change how return air is mixed and to improve airflow.

- Check for open sewer vents inside the building.

- Stop sampling for chemical and biological agents to identify a cause for nonspecific symptoms.

\section{What Employees Can Do}

- Stop using portable ionizing air cleaners; these devices may release ozone that can cause symptoms similar to those reported by building occupants. 


\section{Introduction}

The Health Hazard Evaluation Program received a request from an employer representative at a college to evaluate employees' concerns about health symptoms that were believed to be related to the indoor environmental quality in a campus building. During our visit in May 2013, we evaluated indoor environmental quality conditions in the building and interviewed employees about their work and health.

\section{Background}

In 1982, National Institute for Occupational Safety and Health investigators evaluated the possible occupational causes of symptoms involving the peripheral nervous system in employees who worked in the home economics department that was housed in the building that was the focus of the current concerns [NIOSH 1983]. The 1982 evaluation found no substances in the workplace potentially capable of producing peripheral neuropathy. Moreover, neither results of nerve conduction velocity tests nor the pattern of the reported symptoms suggested that employees had peripheral neuropathy. However, employees continued to associate perceived poor indoor environmental quality with a variety of health concerns, and another health hazard evaluation was requested in 1998 [NIOSH 1998]. In the 1998 evaluation employees believed that exposures to sodium hydroxide, chlorine, hydroquinone, pesticides, methylene chloride, and acrylic were associated with headaches, nausea, burning eyes, chronic respiratory problems, and breast cancer. Investigators found no chemicals or physical agents such as ionizing radiation in the workplace that may have been responsible for cancer or chronic respiratory illness.

\section{Methods}

Our objectives were to evaluate the indoor environmental quality of the building and identify workplace exposures or conditions that could be associated with reported symptoms.

\section{Employee Interviews and Medical Records}

We reviewed the college's summary of symptoms reported by employees and students between July 2011 and February 2013. We also reviewed individual employee and student incident reports filed with the college about the building during the same period.

We obtained a roster of all faculty, managers, and staff who worked in the building between July 2011 and February 2013 from the human resources director. We spoke with the presidents of unions that represented faculty and staff; they identified additional employees who had reported perceived work-related health issues. Some of these employees no longer worked at the college. We scheduled interviews with all current and former employees identified. We asked about health issues they felt were work related, job duties, and personal protective equipment use. We obtained a complete medical history to help detect unrecognized occupational illnesses. Medical records were requested if employees reported seeing a physician for health issues that they attributed to the building. On the basis of our professional judgment, we did not request medical records for health problems not related to 
the building, for example, kidney stones.

\section{Building Walk-through Survey and Ventilation Assessment}

During our walk-through building survey we looked for evidence of past or current water damage, water incursion, and mold. We visually inspected the air handling units and qualitatively evaluated air pressure relationships between building areas using ventilation smoke tubes. We also reviewed a contractor's 2011 ventilation test and balance report done after installation of a new ventilation system.

\section{Indoor Environmental Quality Consultant Reports}

We reviewed the following consultant reports:

- August 2001 (indoor environmental quality evaluation)

- November 2001 (ventilation duct remediation)

- April 2002 (building remediation)

- March 2010 (soil sampling)

- March 2011 (ventilation system test, adjust, and balance report)

- December 2012 (carpet removal)

- February 2013 (indoor environmental quality recommendations)

- March 2013 (plumbing inspection and repair)

- March 2013 (bacteria and mold sampling)

- April 2013 (indoor environmental quality assessment report)

\section{Results}

\section{Employee Interviews and Medical Record Review}

We interviewed 39 of 44 current or former employees identified. Interviewed employees reported working in the building from 3 months to 36 years. Their jobs included administrative work, teaching, and custodial work. Of the 39 interviewed employees, six reported no work-related symptoms. The most common symptoms reported by the other 33 employees were headache (21); eye irritation (8); poor memory or concentration, dizziness or lightheadedness, and inability to find words or difficulty articulating thoughts (7 each); throat irritation (6); nausea and rash (5 each); and shortness of breath and runny nose (4 each). Symptoms or illnesses reported by three or fewer employees included fatigue, achiness, numbness of the lips or tongue, metallic taste in the mouth, sinus problems, postnasal drip, cough, bloody nose, mouth sores, and excessive mood changes. Other medical issues reported by one employee each included nerve compression syndromes, interstitial lung disease, rheumatoid arthritis, elevated liver function test results, worsening lymphedema 
(excess fluid in the lymph system) after breast cancer treatment, hives and angioedema (swelling under the skin), kidney stones, interstitial cystitis (inflammation of the bladder), and worsening of Crohn's disease (an inflammatory bowel disease). One employee each reported new onset asthma, a recurrence of childhood asthma, worsening of asthma at work, and pre-existing asthma that was unchanged at work.

We reviewed the medical records of four employees. One employee who reported new onset asthma was seen by multiple physicians, and findings differed by physician. The medical records did not mention a relationship to the workplace. The second employee was diagnosed with a work-related "chronic inflammatory immune response syndrome." This is not an accepted medical diagnosis. The diagnosis was based on visual contrast sensitivity testing and numerous other nonstandard laboratory tests. The third employee had respiratory problems worsened by heart problems. The medical records noted worsening symptoms at work, but the spirometry records noted no clear pattern of change. The fourth employee had a chronic cough that developed in the late 1990s. A medical evaluation in early 2002 documented some findings consistent with hypersensitivity pneumonitis. Mold contamination throughout the building was noted in a 2001 consultant's report. This employee reported improvement and continued to work in the building without further respiratory problems.

We reviewed 58 incident reports from students; some filed more than one report. The symptoms reported were similar to those reported by interviewed employees: headache, fatigue, irritated eyes, nausea, skin irritation/rashes, bloody noses, etc. One student reported having daily asthma attacks in the building that required use of a rescue inhaler. We also reviewed 57 incident reports from employees; some filed more than one report. We interviewed all but one of the employees who filed a report.

\section{Building Walk-through Survey and Ventilation Assessment}

Constructed in 1968, the two-story concrete building has a flat roof and concrete slab foundation that is partially below ground. It was designed as a health professions training facility containing classrooms, offices, and practical training laboratories. Dental hygiene and dental assistant training programs have been in this building since 1968. The dental clinic has 18 chairs with radiology capability, using both traditional film and digital radiographs and use of amalgam. Nursing, respiratory therapy, medical technology, and other 2-year degree programs also have been based in the building, and at one time a childcare center and a laundry operated in the building.

The college has remodeled the building several times. In the 1990s it contained dental and nursing programs. In 2010, the nursing program moved from the building, leaving dental and medical technology programs. From 2010-2011, the interior of the building was renovated, and a new variable air volume heating, ventilating, and air-conditioning system was installed. Old ventilation ductwork, some underground, was sealed and abandoned. Building maintenance staff found accumulated rainwater in hollow columns on the exterior of the building; these columns were filled with concrete to prevent further water incursion and accumulation. In 2012, the medical technology and dental training programs moved out of the building 
because of continuing indoor environmental quality concerns. At the time of our evaluation the offices, dental clinic, and dental labs were unoccupied. However, classrooms and a computer lab were still in use. The college had removed carpet in most of the unoccupied areas, exposing the bare concrete floor. The entire campus used only "green" cleaning products as part of an integrated pest management program.

The dental clinic and several second floor offices had operable exterior windows that were closed during our visit. We saw no evidence of past or current water damage, water incursion, or mold. We did see portable ionizing air cleaners in use in occupied areas (Figure 1). We also found an open sewer vent pipe inside a floor cabinet in the dental laboratory (Figure 2).

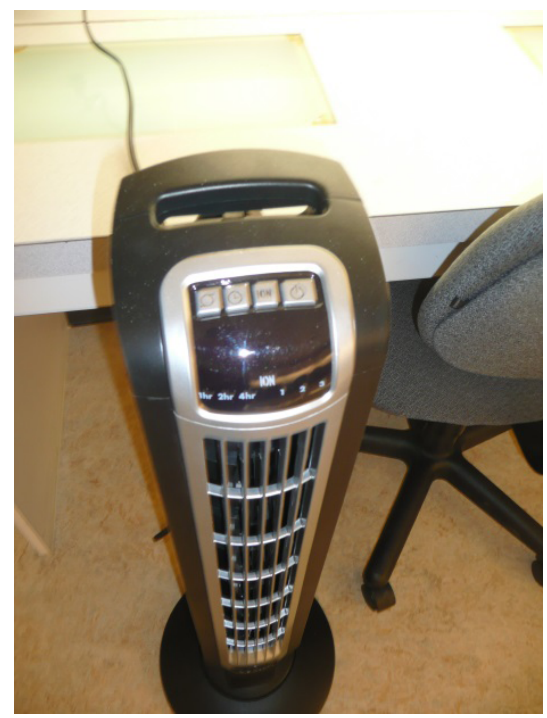

Figure 1. Portable ionizing air cleaner. Photo by $\mathrm{NIOSH}$.

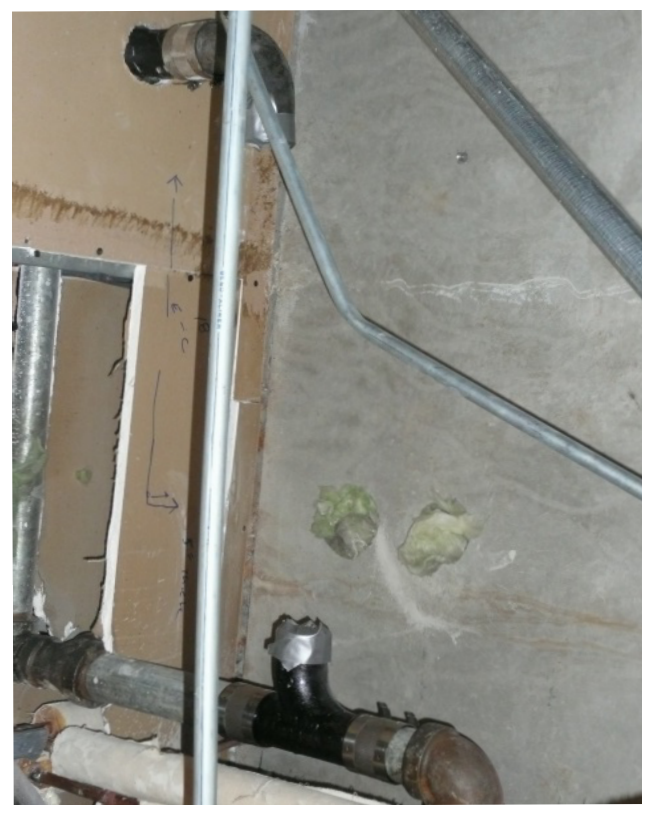

Figure 2. Duct tape used to cover an open end of a vent for a drain. Photo by NIOSH. 
In response to ongoing indoor environmental quality concerns, the facilities maintenance staff operated the building's ventilation system 24 hours per day, 7 days per week, and introduced approximately $50 \%$ outdoor air. The air filters had a minimum efficiency report value of 13 and were changed twice per year. The ventilation system was designed to mix return air from classrooms, offices, and the dental clinic and exhaust air from the dental laboratory directly to the outside. Using ventilation smoke tubes, we found that the dental clinic was not consistently kept under negative air pressure relative to surrounding areas, which meant that the ventilation system could push air out of the dental clinic to surrounding areas. Because the building was mostly unoccupied and the ventilation system was operating continuously, we did not measure occupant comfort parameters, such as temperature and relative humidity, or carbon dioxide, a surrogate used to evaluate the adequacy of the ventilation system in providing an adequate amount of outdoor air to occupied spaces.

\section{Indoor Environmental Quality Consultant Reports}

In general, all of the reports we reviewed shared a common theme of employees experiencing a variety of nonspecific health effects, such as headache, upper respiratory irritation, and eye/ nose/throat irritation that they associated with working in the building. The following is our summary of the more substantive reports:

- July 2001. Microbial samples, including bulk, surface wipe, surface vacuum, and area air samples, were collected. The indoor environmental quality consultants concluded that mold contamination had occurred in all areas of the building, and that the ventilation system needed to be rebalanced or upgraded. This report also recommended repairing roof leaks, replacing water-damaged porous material, improving maintenance of the ventilation system, and increasing the amount of outdoor air provided to building occupants.

- April 2002. This report summarized the remediation projects completed in the building, including repairing and cleaning ductwork and cleaning offices, classrooms, and the mechanical room. The facilities maintenance staff removed the fiberglass insulation that lined the ductwork immediately following the fan housings and in ducts elsewhere in the building.

- March 2011. A test, adjust, and balance to design specifications were performed following the renovation and replacement of the ventilation systems. The ventilation test and balance firm identified ancillary ventilation problems, such as nonfunctioning restroom exhaust fans, and reported them to the heating, ventilation, and air-conditioning mechanical contractor.

- December 2012 to March 2013. Consultants evaluated the ventilation and plumbing systems, investigated carpet odors, collected microbial air and surface samples, and conducted soil sampling (in response to employee concerns of a chlorine-like odor in an area of a former laundry). In addition, investigators from the Occupational Safety and Health Administration consultation program reviewed the chemicals used and procedures followed in the dental area and sampled for mercury, volatile organic compounds, and metals. Ventilation recommendations included raising the height of roof-mounted outdoor air intakes, using more efficient air filters, installing 
a humidification system, and rebalancing the ventilation system. The plumbing inspection identified the drain-waste-vent system as a possible contributor to occupant complaints of sewer gas. Results from the microbial evaluation (air and surface wipe sampling and visual inspection) found no evidence of water incursion or microbial growth. Neither total petroleum hydrocarbons nor volatile organic compounds were detected in the soil. The Occupational Safety and Health Administration investigators found mercury in area air samples collected where cleaning and handling of instruments used with amalgam occurred, and where containers of amalgam capsules and amalgam waste were stored. On the basis of these air sample results for mercury, changes were made to the amalgam recycling and disposal processes. The air sampling results for volatile organic compounds and metals, including lead, chromium, nickel, and copper were below occupational exposure limits.

\section{Discussion}

\section{Employee Interviews}

Employees in offices, schools, and other similar settings [Malkin et al. 1996] have commonly reported many of the symptoms reported by the building employees in this evaluation such as headache, eye and throat irritation, dizziness, lightheadedness, and nausea. A symptom is any subjective sensation or perceived change in bodily function which only the individual can perceive. Research has shown that symptoms are influenced by cognitive processes [Bogaerts et al. 2010]. In this evaluation there was heightened awareness by building occupants of a suspected problem in the building. Such heightened awareness might lead some individuals to notice symptoms they might otherwise overlook and to attribute them to the work environment. We believe that care must be taken when attributing common symptoms to particular exposures because the association is as likely to be coincidental as to be causal.

Of the general population, $86 \%-95 \%$ have one or more common symptoms during any given 2- to 4-week period, and the average adult reports a minimum of one symptom every 4 to 6 days [Barsky and Borus 1995]. These symptoms are rarely caused by serious illness. In fact, $15 \%-50 \%$ of primary care visits are for what is termed "medically unexplained symptoms" [Kirmayer et al. 2004; Jackson et al. 2009; Bogaerts et al. 2010].

Medically unexplained symptoms are those for which no cause is found, even after thorough medical evaluation. Lipscomb et al. reported 1-year symptom prevalence rates from three populations in California [Lipscomb et al. 1992]. The top 10 symptoms were sinus congestion or sneeze, irritated eyes, allergies or asthma, headaches, fatigue, difficulty sleeping, numbness or tingling in limbs, and skin problems, with rates ranging from $9.1 \%$ to $30.4 \%$.

The U.S. Environmental Protection Agency conducted a systematic survey of 100 randomly selected office buildings without known indoor environmental quality complaints in the United States to develop baseline data about U.S. office buildings [Brightman et al. 2008]. The National Institute for Occupational Safety and Health conducted a similar study of 80 buildings with indoor environmental quality complaints [Malkin et al. 1996]. Occupants in both studies reported work-related symptoms. The rank order of symptoms was the same, but 
rates were significantly higher in the buildings with indoor environmental quality complaints. The most common work-related symptoms reported in both studies were dry, itching, or irritated eyes; unusual tiredness or fatigue; headache; tension or irritability; pain in the back, neck, and shoulders; stuffy or runny nose or sinus congestion; sneezing; sore or dry throat; and difficulty remembering things or concentrating. Of the employees in the randomly selected buildings without known complaints, $45 \%$ reported at least one work-related symptom.

Several interviewed employees mentioned memory problems that they attributed to their work environment. Memory problems are commonly encountered in clinical practice and in the general population, and in a study of adults in the Netherlands nearly 39\% reported memory problems [Ponds et al. 1997]. Another study of adults in one U.S. city found that $22 \%$ reported memory problems [Bassett and Folstein 1993]. Bolla examined 199 healthy men and women between the ages of 39 and 89 , and found that $83 \%$ reported forgetting names, $60 \%$ reported forgetting where they put things, 53\% reported forgetting words, $41 \%$ reported forgetting directions to places, $41 \%$ reported forgetting what they were doing, and 34\% reported forgetting appointments [Bolla et al. 1991]. Most studies find that self-reported memory problems are not related to actual performance, but are attributable mainly to depression and mood [Derouesne et al. 1999; Jorm et al. 2001; Comijs et al. 2002].

Another symptom reported by some interviewees was metallic taste or other change in taste perception. This perception is another commonly reported symptom that is difficult to objectively validate [Cowart 2011]. In most cases, no specific cause has been identified. Sometimes, however, metallic taste has been associated with medication use, head trauma, upper respiratory infection, poor oral hygiene, periodontal disease, or diabetes.

Numbness and tingling sensations of the lips and around the mouth, if associated with symptoms of lightheadedness, feeling like passing out, chest tightness, and heart palpitations, could be related to a breathing pattern that is faster or deeper than the body requires (hyperventilation) [Kern and Rosh 2008]. These symptoms can be alarming because they seem to be related to the nervous system, lungs, or heart. Typically, however, medical evaluations do not find these to be serious medical conditions. Most people with this breathing pattern are not aware that they are breathing this way, even when the pattern is triggered by unpleasant odors such as odors from chemicals in and outside the workplace.

Several employees reported specific medical diagnoses that we believed were unrelated to each other and to the building environment, for example, nerve compression syndromes, rheumatoid arthritis, abnormal liver function tests, worsening lymphedema after breast cancer treatment, hives and angioedema, kidney stones, interstitial cystitis, and worsening of Crohn's disease.

\section{Medical Records}

It appeared that laboratory tests and a medical questionnaire used to diagnose "chronic inflammatory immune response syndrome" in one employee were based upon two published studies claiming that biotoxin-related illness, a condition with multiple-organ-system symptoms, is related to water-damaged buildings [Shoemaker and House 2005, 2006]. Both studies used visual contrast sensitivity testing to document and monitor biotoxin-related illness. 
We believe that these studies have methodological limitations, including a nonrepresentative study group, medical conditions that often present with multisystem symptoms (fibromyalgia and chronic fatigue syndrome, for example), the lack of a comparison group, and poor exposure characterization. Replication of findings by other researchers is a critical element in confirming such hypotheses; these results have not been replicated to our knowledge. We used visual contrast sensitivity testing in an evaluation to see if it could be used as a marker of effect from occupancy in water-damaged buildings. We concluded that visual contrast sensitivity testing should not be used for clinical assessment of individuals exposed to water-damaged buildings [NIOSH 2010].

Using medical questionnaires to determine patient symptoms can result in overreporting of symptoms, sometimes up to four times more [Homsi et al. 2006; Nolin et al. 2006; Stapleton and Mills 2008]. Additionally, many of the blood tests this employee underwent are not approved by the Food and Drug Administration, are for research purposes only, or were interpreted in a nonstandard manner.

\section{Building Walk-through Survey}

Although the building had water incursion episodes in 2001, we saw no evidence of past or current water damage, water incursion, or mold in the building during our May 2013 evaluation. We found no evidence of a hazard from the specific chemicals identified by building occupants as concerns. Employees and managers reported intermittent brief use of nitrous oxide and methyl methacrylate. Consultant environmental sampling data did not reveal overexposures and employee interviews did not reveal adverse health effects related to exposure to either of these chemicals. The consultant's air sampling results confirmed low airborne mercury levels. We found no evidence of adverse health effects related to mercury exposure.

Employees were using ionizing air cleaners in some parts of the building. An ionizing air cleaner can produce ozone, a gas that can cause respiratory symptoms such as cough, shortness of breath, chest tightness, throat irritation, and wheeze, and nonrespiratory symptoms such as headache, nausea, malaise, fatigue, dizziness, insomnia, poor concentration, acrid taste in the mouth, and eye irritation [Lipsett 2001]. Many of these nonspecific symptoms were reported by building occupants in this evaluation.

\section{Building Ventilation}

The ventilation system for the dental clinic, classrooms, and offices allowed return air from these disparate areas to mix with outdoor air before redistribution. This design may allow odors and particulate generated within the dental clinic to spread to other areas of the building. Likewise, the variable air volume design in the building, although well suited for offices and classrooms, may not maintain the dental clinic under a consistent neutral or negative air pressure relative to surrounding areas. Maintaining negative pressure in the dental clinic means that air flows from adjacent offices and classrooms into the dental clinic. This would help keep potential airborne contaminants from the dental clinic from spreading to other areas. Although ventilation guidance for dental offices is limited, ideally dental spaces need a separate ventilation system from adjacent spaces. Constant volume air handling 
systems are the simplest way to maintain the desired pressure relationships between dental labs, dental clinics, and surrounding classrooms and offices [ASHRAE 1998].

\section{Indoor Environmental Quality Consultant Reports}

The college had arranged for sampling for chemicals, mold, and bacteria inside and outside this building over the past 13 years. Some of the sampling, for example area air sampling for mercury in the dental clinic, is useful because it is relatable to specific work activities. However, on the basis of previous National Institute for Occupational Safety and Health indoor environmental quality evaluations of offices and classrooms, sampling for chemicals and biological agents often is not useful in identifying causes of reported health problems for the following reasons:

- The sample results can be difficult to interpret with regard to health impact, especially when the levels of exposure are very low.

- In non-industrial work environments the levels of airborne chemicals or biological agents usually are much lower than occupational exposure limits.

- No acceptable levels of biological agents in the air or surfaces have been established.

\section{Conclusions}

Building occupants reported many of the same non-specific symptoms commonly reported by employees who work in offices, schools, and the general population. It is possible that some employee symptoms were related to ozone exposure from the use of portable ionizing air cleaners. We did not identify current problems with the building that could be associated with these symptoms. One employee may have developed hypersensitivity pneumonitis from working in the building in 2001 when mold problems were found. We found no evidence that the other less common or more serious health problems reported by some occupants were work related.

We saw no evidence of past or current water damage, water incursion, or mold in the building. Although the ventilation system appeared well maintained and functioned as designed, two conditions existed that could lead to airborne contaminants in the dental clinic spreading to other areas of the building. The first was return air from the dental clinic mixing with return air from offices and classrooms before recirculation. The second was not keeping the dental clinic under a consistent neutral or negative air pressure relative to surrounding areas, meaning that air from the dental clinic could flow to adjacent areas.

\section{Recommendations}

On the basis of our findings, we recommend the actions listed below. We encourage the college to use a labor-management health and safety committee or working group to discuss our recommendations and develop an action plan. Those involved in the work can best set priorities and assess the feasibility of our recommendations for the specific situation at the college. Our recommendations are based on an approach known as the hierarchy of controls. This 
approach groups actions by their likely effectiveness in reducing or removing hazards. In most cases, the preferred approach is to eliminate hazardous materials or processes and install engineering controls to reduce exposure or shield employees. Until such controls are in place, or if they are not effective or feasible, administrative measures and personal protective equipment may be needed.

\section{Engineering Controls}

Engineering controls reduce employees' exposures by removing the hazard from the process or by placing a barrier between the hazard and the employee. Engineering controls protect employees effectively without placing primary responsibility of implementation on the employee.

1. Consult with a ventilation engineer to review the ventilation system design for the building. An improved design would eliminate the mixing of return air from the dental clinic with return air from offices and classrooms, and maintain the dental clinic under negative pressure relative to surrounding spaces.

2. Check plumbing for uncapped sewer vents inside the building.

\section{Administrative Controls}

Administrative controls refer to employer-dictated work practices and policies to reduce or prevent hazardous exposures. Their effectiveness depends on employer commitment and employee acceptance. Regular monitoring and reinforcement are necessary to ensure that policies and procedures are followed consistently.

1. Stop environmental sampling for chemical and biological agents to identify a cause for non-specific symptoms among faculty, staff, and students.

2. Stop using portable ionizing air cleaners because they may release ozone. 


\section{References}

ASHRAE [1998]. Dental ventilation theory and applications. ASHRAE Journal 48, February 1998. [http://bookstore.ashrae.biz/journal/download.php?file=DentalVentilation.pdf]. Date accessed: February 2015.

Barsky AJ, Borus JF [1995]. Somatization and medicalization in the era of managed care. JAMA 274(24):1931-1934.

Bassett SS, Folstein MF [1993]. Memory complaint, memory performance, and psychiatric diagnosis: a community study. J Geriatr Psychiatry Neurol 6(2):105-111.

Bogaerts K, Van Eylen L, Li W, Bresseleers J, Van Diest I, De Peuter S, Stans L, Decramer M, Van den Bergh O [2010]. Distorted symptom perception in patients with medically unexplained symptoms. J Abnorm Pschyol 119(1):226-234.

Bolla KI, Lindgren KN, Bonaccorsy C, Bleecker ML [1991]. Memory complaints in older adults: fact or fiction? Arch Neuro 48(1):61-64.

Brightman HS, Milton DK, Wypij D, Burge HA, Spengler JD [2008]. Evaluating buildingrelated symptoms using the US EPA BASE study results. Indoor Air 18(4):335-345.

Comijs HC, Deeg DJ, Dik MG, Twisk JWR, Jonker C [2002]. Memory complaints; the Association with psycho-affective and health problems and the role of personality characteristics. A 6-year follow-up study. J Affec Disord 72(2):157-165.

Cowart BJ [2011]. Taste dysfunction: a practical guide for oral medicine (review). Oral Dis $17(1): 2-6$.

Derouesne C, Lacomblez L, Thibault S, LePoncin M [1999]. Memory complaints in young and elderly subjects. Int J Geriatr Psychiatry 14(4):291-301.

Homsi J, Walsh D, Rivera N, Rybicki LA, Nelson KA, Legrand SB, Davis M, Naughton M, Gvozdjan D, Pham H [2006]. Symptom evaluation in palliative medicine: patient report vs. systematic assessment. Support Care Cancer 14(5):444-453.

Jorm AF, Christensen H, Korten AE, Jacomb PA, Henderson AS [2001]. Memory complaints as a precursor of memory impairment in older people: a longitudinal analysis over 7-8 years. Psychol Med 31(3):441-449.

Kern B, Rosh AJ [2008]. Hyperventilation syndrome. eMedicine Emergency Medicine. [http://emedicine.medscape.com/article/807277-print]. Date accessed: February 2015.

Kirmayer LJ, Groleau D, Looper KJ, Dominice Dao M [2004]. Explaining medically unexplained symptoms. Can J Psychiatry 49(10):663-672.

Jackson JL, George S, Hinchey S [2009]. Medically unexplained physical symptoms. J Gen Intern Med 24(4):540-542. 
Lipscomb JA, Satin KP, Neutra RR [1992]. Reported symptom prevalence rates from comparison populations in community-based environmental studies. Arch Environ Health 47(4):263-269.

Lipsett MJ [2001]. Ozone. In: Clinical environmental health and toxic exposures. Sullivan JB, Krieger GR, eds. 2nd rev. ed. Philadelphia, PA: Lippincott, Williams, and Wilkins, pp. 806-818.

Malkin R, Wilcox T, Sieber WK [1996]. The National Institute for Occupational Safety and Health indoor environmental evaluation experience. Part two: symptom prevalence. Appl Occup Environ Hyg 11(6):540-545.

NIOSH [1983]. Health hazard evaluation report: Lane Community College, Eugene, OR. By Apol A, Cone J, Helgerson S, Keenlyside, Cincinnati, OH: U.S. Department of Health and Human Services, Centers for Disease Control, National Institute for Occupational Safety and Health, NIOSH HHE Report No. 81-447-1273.

NIOSH [1998]. Health hazard evaluation letter of July 17, 1998, from EJ Esswein, NIOSH to Lane Community College, Eugene, Oregon, NIOSH HETA 98-0176.

NIOSH [2010]. Health hazard evaluation report: comparison of mold exposures, workrelated symptoms, and visual contrast sensitivity between employees at a severely waterdamaged school and employees at a school without significant water damage, New Orleans, LA. By Thomas G, Burton NC, Mueller C, Page E. Cincinnati, OH: U.S. Department of Health and Human Services, Centers for Disease Control and Prevention, National Institute for Occupational Safety and Health, NIOSH HHE Report No. 2005-0135-3116.

Nolin P, Villemure R, Heroux L [2006]. Determining long-term symptoms following mild traumatic brain injury: method of interview affects self-report. Brain Inj 20(11):1147-1164.

Ponds RWHM, Mommissaris KJAM, Jolles J [1997]. Prevalence and covariates of subjective forgetfulness in a normal population in the Netherlands. Int J Aging Hum Dev 45(3):207-221.

Shoemaker RC, House DE [2005]. A time-series study of sick building syndrome: chronic, biotoxin-associated illness from exposure to water-damaged buildings. Neurotoxicol Teratol 27(1):29-46.

Shoemaker RC, House DE [2006]. Sick building syndrome and exposure to water-damaged buildings: time series study, clinical trial and mechanisms. Neurotoxicol Teratol 28(5):573-588.

Stapleton R, Mills R [2008]. Role of open-ended questionnaires in patients with balance symptoms. J Laryngol Otol 122(2):139-144. 
Keywords: North American Industry Classification System 611310 (Colleges, Universities, and Professional Schools), Oregon, indoor environmental quality, dental clinic, ventilation 
This page left intentionally blank 
The Health Hazard Evaluation Program investigates possible health hazards in the workplace under the authority of the Occupational Safety and Health Act of 1970 (29 U.S.C. § 669(a) (6)). The Health Hazard Evaluation Program also provides, upon request, technical assistance to federal, state, and local agencies to investigate occupational health hazards and to prevent occupational disease or injury. Regulations guiding the Program can be found in Title 42, Code of Federal Regulations, Part 85; Requests for Health Hazard Evaluations (42 CFR Part 85).

\section{Disclaimer}

The recommendations in this report are made on the basis of the findings at the workplace evaluated and may not be applicable to other workplaces.

Mention of any company or product in this report does not constitute endorsement by the National Institute for Occupational Safety and Health (NIOSH).

Citations to Web sites external to NIOSH do not constitute NIOSH endorsement of the sponsoring organizations or their programs or products. NIOSH is not responsible for the content of these Web sites. All Web addresses referenced in this document were accessible as of the publication date.

\section{Acknowledgments}

Desktop Publisher: Shawna Watts

Editor: Ellen Galloway

Logistics: Donnie Booher

\section{Availability of Report}

Copies of this report have been sent to the employer and employees at the facility. The state and local health department and the Occupational Safety and Health Administration Regional Office have also received a copy. This report is not copyrighted and may be freely reproduced.

This report is available at http://www.cdc.gov/niosh/hhe/reports/pdfs/2013-0074-3229.pdf.

\section{Recommended citation for this report:}

NIOSH [2015]. Health hazard evaluation report: evaluation of indoor environmental quality in a college teaching and administrative building. By Niemeier RT, Page E, Burr GA. Cincinnati, OH: U.S. Department of Health and Human Services, Centers for Disease Control and Prevention, National Institute for Occupational Safety and Health, NIOSH HHE Report No. 2013-0074-3229. 
Delivering on the Nation's promise:

Safety and health at work for all people through research and prevention

To receive NIOSH documents or more information about occupational safety and health topics, please contact NIOSH:

Telephone: 1-800-CDC-INFO (1-800-232-4636)

TTY: 1-888-232-6348

CDC INFO: www.cdc.gov/info

or visit the NIOSH Web site at www.cdc.gov/niosh

For a monthly update on news at $\mathrm{NIOSH}$, subscribe to

$\mathrm{NIOSH}$ eNews by visiting www.cdc.gov/niosh/eNews. 